\title{
Reformat arsimore mes dy periudhave historike - Arsimi shqiptar nëpërmjet dorëshkrimeve
}

Besnik Bashaliu

Në këtë punim që po i prezantohet sot lexuesit të Albanon, synohet që nëpërmjet udhëtimit në dokumente zyrtare të rralla arkivore, të evidentohen procese të rëndësishme të transformimit të sistemit arsimor shqiptar gjatë viteve 1934 - 1940, që përkojnë me dy periudha të rëndësishme të historisë së Shqipërisë, atë të monarkisë zogiste dhe viteve të para të pushtimit fashist.

Mbështetur në nje dokument origjinal të Zyrës Arsimore të Prefekturës së Elbasanit, gjendur në muzeun e shkollës 9-vjeçare "Naim Frashëri”, ështëarritur që nëpërmjet studimit të titujve të korrespondencës zyrtare, të pasqyrohen mjaft elemente të rëndësishme të praktikës protokollare administrative, si dhe të përmbajtjes së proceseve mësimore-edukative në institucionet shkollore. Sigurisht, që me anë të këtij punimi modest, nuk pretendojmë të japim gjithë karakterin e një tradite në lëmin e arsimit shqiptar, por të prekim disa aspekte të veçanta që na duken me interes në kuadrin e një shkolle që pëson transformime të vazhdueshme nën ndikimet politiko-shoqërore. Hulumtimi nëpër rreshtat e burokracisë së kohës, na jep një panoramë më të plotë jo vetëm të proceseve reformuese në arsimin shqiptar të ndërmarra në vitet 1932-1933 , por edhe ndikimet e kulturës religjioze e asaj ideologjike fashiste në shkollën shqiptare para dhe pas pushtimit.

Në periudhen e lulëzimit të mbretërisë shqiptare, vitet 1928-1939, një vend të rëndësishëm, iu kushtua edhe arsimit shqiptar, si një fushë, e cila do të përbënte në vetvete një përpjekje titanike që synonte ta vendoste arsimin shqiptar në shinat e zhvillimit europian perëndimor. Mbretëria do t’i jepte

Histori e popullit shqiptar, vol. III, f.412. 
një vend të veçantë rolit të shkollës në dobi të edukimit e civilizimit të një shoqërie që progresonte mes mjergullës feudo-borgjeze e dëshirave për të bërë përpara, me shikimin nga oksidenti i zhvilluar. Etapat e vështira në të cilat kaloi formimi e konsolidimi i shtetit shqiptar në të gjitha periudhat e tij, pati në qendër të vëmendjes një proces ku sfidën kryesore e përbënte lufta për emancipimin e një shoqërie që ende vuante nën ndikimet e së kaluarës shekullore otomane. E në këtë konteks, reformat në drejtim të modernizimit të shtetit shqiptar do të shkonin në të njëjtën kahje me ato në fushën e arsimit, qoftë edhe përkohësisht. Natyrisht që reformat në fushën e arsimit në Shqipëri nuk u zhvilluan në një terren të qetë për shkaqe që lidheshin jo vetëm me mjedisin shoqëror, konsevatorizmin e prapambetjen kulturore që gjeneronte kundërshti për gjithçka të re e përparimtare që zbatohej në strukturën arsimore, por edhe nga synime të mirëfillta ideologjike e politike, të iniciuara këto veçanërisht në shkollat private, qofshin ato me karakter fetar apo edhe profesional, si në jug ashtu edhe në veri të Shqipërisë. Prandaj, në këto kushte, reforma arsimore e zhvilluar gjatë vitit 1932-1933 merr rëndësi, pasi përbën një përpjekje të rëndësishme për ta vendosur shkollën në baza kombëtare, duke e mënjanuar atë nga ndikimet fetare e politike, qoftë me prirje nacional - shoviniste ashtu edhe fashiste. Veçanërisht të rëndësishme në këtë periudhë ishin dekretet që ndryshonin nenet 206 dhe 207 të ligjit për arsimin që i jepnin shtetit atributet për të përballuar në mënyrë ekskluzive procesin e mësimit e edukimit të shtetasve shqiptarë. Mbyllja e shkollave private që deri në këtë periudhë kishin funksionuar si institucione ku gjallëronin ndjenjat antikombëtare dhe i fryhej pa pushim ndasive fetare e atyre nacionale, ishte një hap i rëndësishëm i reformës arsimore që njihet si reforma Ivanaj ${ }^{2}$. Kjo reformë natyrisht që do të shkaktonte kundërshti, aq më shumë në një kohë kur masat e ndërmara në kuadër të kësaj reforme cënonin institucionet arsimore private, të financuara qoftë nga Roma apo edhe Athina.

Një tjetër element studimor me interes në këtë punim përbën periudha e pushtimit fashist deri nëvitet 1940 dhe raportet që krijon kultura e propaganda fashiste me institucionet shkollore. Sipas lëndës së korrespondencës zyrtare të pasqyruar në dokumente, vihet re një frymë ndikuese në të githë strukturën programore shkollore dhe një proces fashistizimi për të gjithë veprimtarinë mësimore edukative dhe kuadrin arsimor.

Me shumë interes në këtë material të korrespondencës zyrtare, është fakti i rikonceptimit të mendësisë për shkollën shqiptare të anatemuar nga

2 Historia e Popullit Shqiptar, vol.III, f.412. 


\section{Albanon}

\section{Revistë kulturore}

regjimi komunist në periudhën e monarkisë. Kujdesi i treguar për edukimin e fëmijeve me frymë kombëtare e civilizim shoqëror përbën një tregues domethënës për punën e palodhur të bërë nga trupat pedagogike të këtyre institucioneve në dobi të mirërritjes së brezave. Sanksionet ligjore për kundravajtje të rëndësishme në procesin mësimor- edukativ janë barometër për një shkollë që synonte të kryente me devocion misionin e saj kundrejt familjes e shoqërisë shqiptare. Nëpërmjet rreshtave të këtyre dokumenteve, gjejmë të modeluar një shërbim cilësor të përgjegjshëm ndaj së ardhmes së një kombi, ashtu sikurse evidentojmë një strukturë kurajoze që merr mbi vete rolin e mësimdhënësit dhe edukatorit në kushtet e një shoqërie që kishte shumë për të bërë në rrugën e modernizimit e civilizimit oksidental.

\section{Libri i protokolleve}

Libri i protokolleve i gjendur në muzeun e shkollës 9-vjeçare "Naim Frashëri”, dokument ky në të cilin përfshihet e gjithë korrespondenca e Zyrës Arsimore të Prefekturës së Elbasanit, nga periudha e viteve 1934-1940, është një tregues i rëndësishëm i faktit se në monarkinë zogiste institucioni i shtetit ishte i përfaqësuar nga një administratë e praktikë zyrtare korrekte e serioze në kundërshti me propogandën denigruese të regjimit komunist, ku regjimi monarkist anatemohej si i vjetëruar, pa sens shtetëror dhe me ngjyrime otomane. Ky dokument ka përmasa të formatit $44 \times 60 \mathrm{~cm}$ në gjendje të hapur dy fletësh. Është shkruar me shkrim dore duke përdorur penën dhe bojën e shkrimit. Kaligrafia në të shumtën e rasteve lë për të dëshiruar për shkak të vështirësisë në deshifrimin e objektit të shkresës. Gjuha e përdorur në pasqyrimin e titujve të shkresave të dërguara e të marra është ajo shqipe, ku mbizotëron dialekti gegërisht, por vihet re, jo rrallëherë, edhe përdorimi i gjuhës së trevës së Elbasanit. Herë pas here kemi ndryshime të kaligrafisë së shkrimit dhe ngjyrës së bojës së përdorur. Në periudha të ndryshme kohore, në faqet e këtij regjistri janë të shkruara fjalët "U inspektua", data e inspektimit dhe firma e inspektuesit, gjë që tregon se ky dokument zyrtar ka qënë i survejuar sipas një praktike zyrtare kontrolli. Kjo korrespondencë e pasqyruar sipas rubrikave përkatëse: $n r$ rendor, data e të mbrrijturit, dërguesi (zyra, nr., data), shkurtimi i landës, mënyra e të kryemit (landa, kujt i dërgohet, data) është një marrëdhënie dokumentare mes institucioneve përkatëse arsimore eprore (Ministria e Arsimit, Inspektoriati Shtetëror i Arsimit) drejtuar atyre vartëse (Zyrës Arsimore të prefekturës dhe institucioneve të varësisë së shkollave). 
Materiali i pasqyruar në këtë libër protokollar përbën interes në fushën e studimeve historike, pasi në mënyrë direkte dhe indirekte me anë të titujve të korrespondencës zyrtare, njihemi me periudha ndryshimesh të rëndësishme në fushën e arsimit shqiptar, por edhe me kontributin e shkollës shqiptare në procesin e edukimit dhe formimit të një shoqërie, në etapa historike nëpërmjet të cilave ka kaluar shteti shqiptar nga regjimi monarkist në atë të pushtimit fashist italian. Ajo çka është e rëndësishme në rreshtat e këtyre dokumenteve ka të bëjë me vazhdimësinë e procesit arsimor pavarësisht pushtimit fashist.

Në hulumtimin rigoroz të materialit shkresor të pasqyruar në këtë dokument, një vend të konsiderueshëm zë praktika e zakonshme administrative që lidhet me çështje të veprimtarisë burokratike në lëmin e arsimit (lista kuadri, emërime-shkarkime, transferime, pagesa, leje të zakonshme, dorëzime statistikash tremujore nga ana e shkollave, udhëzime të zakonshme për mbarëvajtjen e vijueshmërisë së nxënësve nëpër shkolla etj.).

Në tërësinë e materialit të studiuar në përputhje me brendinë lëndore, u bë i mundur një klasifikim problematikash, të pasqyruara në shkresat zyrtare dhe që lidhen me:

1. Procesin e formimit e edukimit të kontigjentit shkollor me frymën e ndjenjës kombëtare;

2. Procesin e emancipimit e edukimit qytetar në rrethanat e një shoqërie të prapambetur;

3. Procesin e etikës së sjelljes dhe komunikimit të personelit arsimor në shkolla;

4. Transformimet në lëmin e arsimit dhe diktati i futjes së ideologjisë fashiste gjatë regjimit të pushtimit.

$\mathrm{Një} \mathrm{vend} \mathrm{të} \mathrm{rëndësishëm} \mathrm{zë} \mathrm{në} \mathrm{këto} \mathrm{dokumente} \mathrm{vëmendja} \mathrm{që} \mathrm{institucionet}$ arsimore tregonin për edukimin me frymën kombëtare të nxënësve të shkollave në të gjitha nivelet e arsimit shqiptar. Është koha kur mbretëria shqiptare kishte vendosur lidhje shumë të ngushta me Italinë fqinje dhe ndikimi i politikës italiane për rritjen e shkallës së influencës në arsim ishte rrezik evident. Nga ana tjetër, shkollat private e me karakter fetar nuk ishin nën kujdesin e Ministrisë së Arsimit e si të tilla përbënin një çerdhe ku gëlonte antikombëtarizmi. Pavarësisht reformave të ndërmarra në lëmin e arsimit, gjatë viteve 1932-1933 dhe që synuan ta vendosin shkollën nën ndikimin kombëtar e laik, procesi i edukimit me ndjenjën kombëtare dhe kujdesit për ta shfaqur atë me çdo mënyrë, përbënin vazhdimisht një detyrim konstant 


\section{Albanon}

Revistë kulturore

për institucionet arsimore të shtrirë gjatë gjithë periudhës monarkiste.

- Ministria e Arsimit, Qarkore. Nr.5595 Dt.19.XI.1934 "Mbi mbledhjen e gjanave arkeologjike" ${ }^{3}$

- Inspektoriati, Qarkore. Nr.121/5 Dt.1.III.1937 "Mbi mësimin mirë nga nxënësit të hymnit mbretnor e të Flamurit". ${ }^{4}$

- Ministria e Arsimit, Qarkore. Nr.114 Dt.14.I.1935 "Mbi mënyrën e përshëndetjes në shkolla"5

- Ministria e Arsimit, Qarkore. Nr.166 Dt.22.III.1937 "Mbi përshëndetjen shqiptariste". ${ }^{6}$

- Ministria e Arsimit, Qarkore. Nr.152 Dt.18.III.1937 "Mbi emnat shqip që duhet t'i ngjisen fëmijëve" ?

- Inspektoriati, Qarkore. Nr.361/1 Dt.22.I0.1937 "Për vajzat do të përdoren si kostume bluza e kuqe dhe fundi i zi". ${ }^{8}$

- Inspektoriati, "Dërgohen lista me emra shqip".

Ajo çka përbën interes në këto vëzhgime dhe që japin një ide më të qartë të zhvillimit të arsimit në Shqipëri, janë qarkoret e dërguara nga Ministria e Arsimit dhe Inspektoriati Shtetëror i Arsimit, lënda e të cilave lidhet me procesin edukativ qytetar në shkollën shqiptare për periudhën në fjalë. Nëpërmjet titujve të shkresave e qarkoreve të dërguara për zbatim, kuptojmë rëndësinë që kishte për institucionin më të lartë arsimor në Shqipëri, edukimi qytetar i nxënësve të shkollave me norma e rregulla të një shoqërie të civilizuar krahas procesit të mësimdhënies.

- Ministria e Arsimit, Qarkore. Nr.291 Dt.25.II.1935 "Mbi mos përdorimin e falëve të ndyra nga ana e nxansve". ${ }^{10}$

- Inspektoriati, Qarkore. Nr.966/5 Dt.3.11.1935 "Mbi daljen zbuluar të grave". ${ }^{11}$

- Inspektoriati, Qarkore. Nr. 153 Dt.15.III.1937 "Mbi mos hedhjen gurë mbi tabelat e rrugës". ${ }^{12}$

\footnotetext{
3 Libri i protokolleve.

4 Po aty.

5 Po aty.

6 Libri i protokolleve.

7 Po aty.

8 Po aty.

9 Po aty.

10 Po aty.

11 Po aty.

12 Po aty.
} 
- Inspektoriati, Qarkore. Nr.179 Dt.26.III.1937 “Dërgohen kopje të ligjit për mos mbulimin e fytyrës." ${ }^{13}$

- Inspektoriati, Qarkore. Nr.165 Dt.22.III.1937 "Mbi masat që duhen marrë për ata nxanës që nuk sillen mirë jashtë shkolle". ${ }^{14}$

- Inspektoriati, Qarkore. Nr.54/2 Dt.13.I.1937 "Mbi ndalimin e bixhozit nga ana e nxansve". ${ }^{15}$

- Inspektoriati, Qarkore. Nr.244/1 Dt.14.2.1935 "I dërgohet komisionit lutja e Hysen Abaz Bilani për shkak të gjobës së vume nga mos vijimi në rregull i djalit të tij, Shefqet Bilani”. ${ }^{16}$

$\mathrm{Një} \mathrm{tjetër} \mathrm{problematikë} \mathrm{që} \mathrm{prezantohet} \mathrm{në} \mathrm{korrespondencën} \mathrm{zyrtare} \mathrm{të}$ institucionit arsimor me organizmat vartës lidhet me karakterin e etikës e sjelljes së arsimtarëve në institucionin arsimor, si dhe emërtime të shkollave, përvjetorë të të cilave festohen edhe sot. Duke i dhënë një rëndësi të dorës së parë etikës së sjelljes së arsimtarëve në shkollë, Ministria e Arsimit, synonte të ngrinte në një shkallë më të lartë procesin e ndërgjegjësimit të kuadrit në marrëdhëniet në institucion me të gjithë aktorët e shkollës, duke e mbajtur larg shkollën nga indoktrinimet qofshin me baza fetare, ideologjike e politike. Shkolla konsiderohej si një mjedis i cili detyrimisht duhej t'i shërbente formimit, edukimit dhe ngritjes së nivelit kulturor e arsimor të nxënësve.

- Ministria e Arsimit, Qarkore Nr.5705 Dt.30/XI/1934 "Për nëpunësit dhe familjet e tyre taksat e shërbimit zbriten 50\%”."17

- Inspektoriati, Qarkore Nr.836/1 Dt.16/9/1935 "Shkolla fillore Nr.1 mas këndaj do të quhet "N. Frashëri”, ushtrimorja "Kristoforidhi", femnorja "Drita" dhe shkolla e re "Qemal Baholli". ${ }^{18}$

- Inspektoriati, Qarkore Nr.195 Dt.27.6.1936 "Politika asht e ndalume nëpër shkolla”. ${ }^{19}$

- Inspektoriati, Qarkore Nr.72 Dt.2.II.1937 “Mbi disa ndryshime në ligjin e pensioneve". ${ }^{20}$

- Inspektoriati, Qarkore Nr.176/1 Dt.30.III.1937 "Mbi sjelljen e arsimtarëve". ${ }^{21}$

13 Po aty.

14 Po aty.

15 Po aty.

16 Po aty.

17 Libri i protokolleve.

18 Po aty.

19 Po aty.

20 Po aty.

21 Po aty. 


\section{Albanon}

Revistë kulturore

- Inspektoriati, Qarkore Nr.119 Dt.17.II.1937 "Mbi ndalimin e botimit e mirazhimit të librave e broshurave të padobishme". ${ }^{22}$

- Inspektoriati, Qarkore nr.436 dt.10.01.1940 "Si masë disiplinore të mos përdoret rrahja e fyemja me fjalë të randa për nxansit. Për kundraveprusit merren masa disiplinore" ${ }^{23}$

Në periudhën e viteve 1939-1940, nën regjimin e pushtimit, u rritën përpjekjet për shtrirjen e procesit të ideologjizimit me doktrinën fashiste në strukturën, përmbajtjen dhe personelin e institucioneve arsimore. Ky fenomen evidentohet nëpërmjet urdhrave e udhëzimeve të pasqyruara në dokumente zyrtare.

- Inspektoriati, Qarkore Nr.340/1 Dt.17. XI.1939 “Të gjithë librat e këndimit Mbretnisë Shqiptare dhe abetaret që gjinden ndër duart e nxansve të mblidhen e t’i dërgohen Inspektorisë për t’i djegur. Çdo veprim i kundërt shkakton përgjegjësi”. ${ }^{24}$

- Inspektoriati, Qarkore Nr. 328 Dt.11.10.1939 "Sipas dekretit të Mbretnisë të mos përdoren ma emnat e ri të qyteteve e të katundeve" ${ }^{25}$

- Inspektoriati, Qarkore Nr.568 Dt.15.7.1939 "Në ditët e festave zyrtare të përmenduna në ligjin 6/XI/1928 të vihet vetëm flamuri shqiptar dhe në festat e përbashkta të vihen të dy flamujt tue qenë i Italisë në të djathtë, në një shtizë të veçantë”. ${ }^{26}$

- Inspektoriati, Qarkore Nr. 269 Dt.17.7.1939 “Në dokumentet zyrtare të përdoret edhe viti i epokës fashiste. Sot jemi në vitin XVII të epokës fashiste. Në 29/x/1939 fillon viti XVIII i kësaj epoke. Kjo shënohet mbas datës së zakonshme me shifra romake". ${ }^{27}$

- Inspektoriati, Qarkore Nr. 381 "Sipas urdhnit të federatës fashiste, gjithë arsimtaret deri ne festën e flamurit të kenë veshë devizën". ${ }^{28}$

\footnotetext{
22 Po aty.

23 Po aty.

24 Po aty.

25 Libri i protokolleve.

26 Po aty.

27 Po aty.

28 Po aty.
} 


\section{Përfundime}

Rëndësia e studimit të brendisë së korrespondencës të pasqyruara në këtë dokument origjinal, siç edhe theksuam më lart, lidhet me informacionin e pasur që na japin titujt e këtyre shkresave për të gjykuar e vlerësuar transformimet e arsimit shqiptar në periudha të ndryshme kohore dhe ndikimin e tyre në emancipimin shoqëror. Nisur nga hulumtimet modeste të kryera mbi këtë dokument arrijmë në disa përfundime që lidhen me:

1. Një proces aktiv funksionimi e administrimi të institucioneve shtetërore sipas një kulture shtetbërëse.

2. Reformimin e arsimit shqiptar, ku në qendër të edukimit të ishte fryma kombëtare dhe shkolla laike.

3. Kujdesin e vazhdueshëm për një proces sa më të gjerë formimi e edukimi me norma e rregulla të civilizimit e kulturizimit shoqëror.

4. Përsosmërinë e vazhdueshme të figurës e imazhit të punonjësit arsimor si pasqyrë e një shoqërie të civilizuar.

\section{Bibliografi}

1. Historia e Shqipërisë, vol.III, Tiranë, 2007.

2. Libri i protokolleve, Muzeu i shkollës "Naim Frashëri”, Elbasan, 2015.
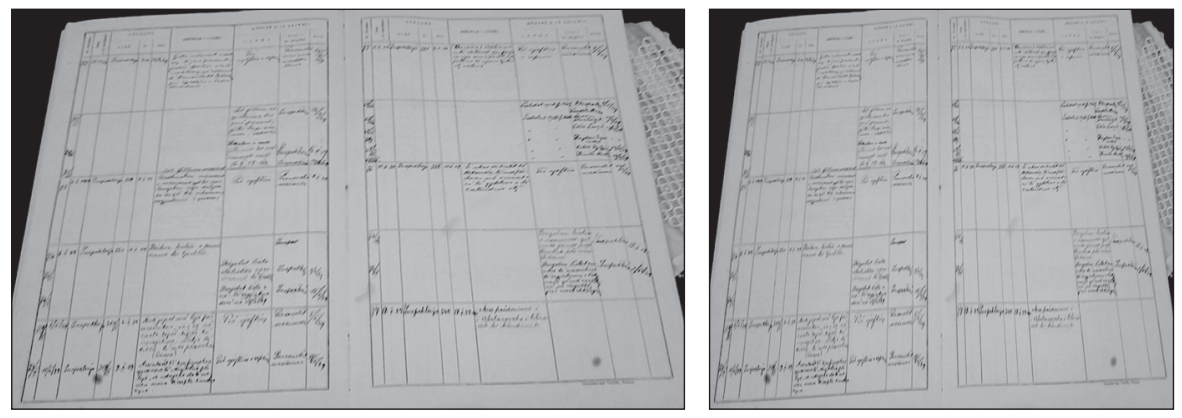

Pamje të Librit të protokolleve, të Zyrës Arsimore të Prefekturës Elbasan 